\title{
FACTORS AFFECTING LENGTH OF HOSPITAL STAY FOR PEOPLE WITH SPINAL CORD INJURIES AT KANOMBE MILITARY HOSPITAL, RWANDA
}

\begin{abstract}
In patients with spinal cord injuries increased length of hospital stay is often as a result of secondary complications such as pressure sores, urinary tract infection and respiratory infection. An increased length of hospital stay was observed at Kanombe Military Hospital in Rwanda. The aim of this study was to determine specific factors affecting length of hospital stay for individuals with spinal cord injuries at Kanombe Military Hospital in Rwanda. The records of 124 individuals with spinal cord injuries who were discharged from the hospital between $1^{\text {st }}$ January1996

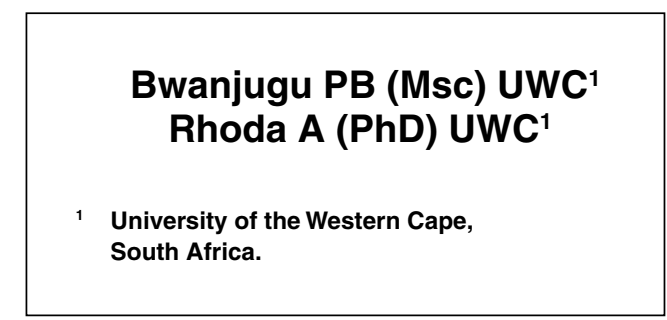
and $31^{\text {st }}$ December 2007 were reviewed to collect data. Information collected and captured on a data gathering sheet included demographic data, information relating to the injury, occurrence of medical complications and length of hospital stay. Linear regression analysis was computed in SPSS to determine factors affecting the length of stay. The necessary ethical considerations were adhered to during the implementation of the study. Current employment status and the occurrence of pressure sores were significantly associated with the length of hospital stay ( $p=0.021$ and $p=0.000$ respectively). A strong relationship was noted between pressure sores and length of stay $(R=0.703)$. There is a need for all members of the rehabilitation team to devise and implement effective measures to prevent the development of pressure sores, in patients with spinal cord injuries in the study setting.
\end{abstract}

\section{KEY WORDS: SPINAL CORD INJURIES, LENGTH OF HOSPITAL STAY, RWANDA.}

\section{BACKGROUND}

Spinal Cord Injury (SCI) is a devastating condition that requires intensive and specialized clinical rehabilitation. It occurs most frequently to young, healthy individuals around the world (Post et al 2005; Ragnarrsson et al 2005). A SCI leaves individuals with a wide range of impairments, activity, limitations and participation restrictions (Kirchberger et al 2010). Common impairments experienced by individuals with a spinal cord injury include changes in emotional, sensory, defecation, urinary, motor and sexual functions. Individuals who have suffered a spinal cord injury could also have activity limitations and participation restrictions relating to self care, mobility, interpersonal relationships and community, social and civic life (Scheuringer et al 2010).

The devastating changes caused by SCI also predispose the individuals to the development of various secondary medical complications throughout life. These may interfere with health and well-being, social activity, produtive employment and quality of life (Middleton et al 2004; Ackery et al 2004). Patients are often re-admitted to hospital due to complications with the genitourinary, gastrointestinal, skin, musculoskeletal, neurological, respiratory and cardiovascular systems (Middleton et al 2004; Savic et al 2000). The occurrence of pressure sores is among the most common long-term secondary medical complication in persons with SCI (Garber and Rintala 2003).

The majority of patients with SCI receive hospital rehabilitation to address the impact of the injury on the person (Joseph 2011; van Langeveld et al 2011, Henn et al 2012). The rehabilitation of patients with SCI aims to enable the fullest range of activities and active participation in all aspects of human life (Chappell and Wirz 2003). The provi- sion of services including rehabilitation is however challenging in developing countries (Kautzky and Tollman 2008) especially in the transitional period after a war where rehabilitation centers do not have adequate staff, facilities or equipment to assist individuals who have spinal cord injuries (Adler et al 2004).

Length of stay following spinal cord injury varies. For instance the mean LOS for spinal cord injury ranges from, 56-61 days in Australia (New et al 2002), and 91-143 days in Italy (Celani et al 2001) 106-239 in Israel (Ronen et al 2004), and in the Western Cape South Africa a mean of 73 days for patients admitted to a specialized in-patient faci-

Correspondence Author:

P.B. Bwanjugu

Kanombe Military Hospital P.O BOX, 3377 Kigali-Rwanda

Email: patbwanjugu@gmail.com 
lity in the Western Cape (Joseph 2011) and a mean of 95 days for those admitted to a Private Rehabilitation Hospital (Henn et al 2012). There is limited published literature relating to the LOS in other African countries. Factors reported to be associated with LOS in hospital for patients after SCI are personal factors and hospital factors. The personal factors include age, severity of injury and the development of secondary medical complications, notably urinary tract infections and pressure sores (Herm, et al 2000) whereas hospital factors include being treated in a public or private hospital, the availability of beds and the staffing levels (Simpson et al 2005).

While working as a physiotherapist in the physiotherapy department at Kanombe Military Hospital (KMH) between 2002 and 2006, the researcher noted that the majority of SCI are hospitalized for many years. The motivation for the study was therefore to determine length of stay and factors affecting the length of hospital stay among spinal cord injured patients at this hospital as the patients are admitted for a much longer period than what is reported in the literature. This extended length of hospital stay at $\mathrm{KMH}$ results in increased medical costs (Wong et al 2011).

\section{METHODS}

\section{Research Setting}

The study was conducted at the Kanombe Military Hospital in Rwanda. The spinal rehabilitation unit is located within this hospital. The hospital has a bed capacity of four hundred in-patients. It is an acute hospital with departments such as medicine, surgery and gynecology. Patients admitted to the spinal unit are managed by a multidisciplinary team comprising of physiotherapists, nurses, psychotherapists and doctors. The team comprised of two general practitioners, one physiotherapist, 8 nurses and two psychotherapists.

\section{Study design and sample}

This study utilized a quantitative retrospective study design. All patient records of individuals who sustained a spinal cord injury, and who were dis- charged from Kanombe Spinal Cord Rehabilitation Unit (KSCRU) from $1^{\text {st }}$ January 1996 to $31^{\text {st }}$ December 2007 were perused and relevant information was extracted. The period 1996-2007 was chosen by the researcher as hospital records were not always kept up to date as a result of the war and genocide which occurred during 1994.

\section{Instrumentation}

A self-developed data-gathering sheet was used to collect the data. The researcher developed this instrument based on a previous study (Middleton et al., 2004). The final data-gatheringsheet was divided into sections A and B. Section A captured socio-demographic data such as age, gender, education level, employment status and the causes of SCI. The level of the lesion, which was determined clinically, was documented as either paraplegia or tetraplegia. Section B identified LOS and occurrence of secondary complications such as pressure sores, urinary tract infections, and respiratory infections which could have occurred at any stage during the patients admission to hospital. To achieve face and content validity, the data gathering sheet was sent to experts in the field of rehabilitation of SCI patients. These experts included a physiotherapist working at a high intensity rehabilitation centre and a senior lecturer, both who had experience in the rehabilitation of patients with SCI. These experts were satisfied that the instrument would capture the data needed to address the aim of the study. To ensure the reliability of the instrument, the researcher and research assistant compared data collected from the same five patient records prior to the commencement of the study. Due to the small sample size no statistical tests were used to determine the level of reliability. (Professor Madsen, Department of Statistics, University of the Western Cape, personal communication, 30 October, 2008). The consistency of the documented data was very high indicating a high level of inter-rater reliability.

\section{Procedure of data collection}

Prior to data collection, permission to conduct the study and ethical clearance was obtained. The researcher trained one physiotherapist who was not associated with the health setting where the study took place as the research assistant. Training of the research-assistant helped him understand the topic as well as the aims and ethical considerations of the study. Arrangements were made with the staff at the hospital for accessing the folders. After receiving all necessary written documents authorizing the researcher and the research assistant to carry out the study in the Military Hospital, and adhering to all the necessary ethical considerations, appointments were made with the archives officers for data extraction from patients' medical folders.

\section{Data Analysis}

Data were numerically coded and captured using the Statistical Package for Social Sciences version 15.0 (SPSS) software programme for Windows. Descriptive statistics of the data namely frequencies expressed as percentages were used to present information regarding demographic characteristics of the data. Means as a measure of central tendencies were used to calculate the average age of the sample, and the length of stay (LOS). The chi-square test was used to identify whether there were any associations between demographic data and-, occurrence of secondary medical complications with the length of stay. Alpha was set at 0.05 . The linear regression analysis was used to determine factors affecting the length of hospital stay.

\section{Ethical considerations}

Ethical clearance was obtained from the relevant committees at the University of the Western Cape, South Africa. Permission was obtained from the Minister of Health in Rwanda as well as from the director of medical services in Rwandan Defense Force (RDF) in the Ministry of Defense. Further permission was obtained from the director of Kanombe Military Hospital where the study was conducted. To ensure anonymity and confidentiality of the data, no names were documented during the capturing and analysis of the data. 


\section{RESULTS}

\section{Demographic status of the participants}

A total of 142 folders of patients with SCI admitted to Kanombe Spinal Cord Rehabilitation Unit (KSCRU) from $1^{\text {st }}$ January 1996 to $31^{\text {st }}$ December 2007 were accessed. The folders of 18 patients were excluded from the study due to missing data. The final sample therefore consisted of 124 participants. The information relating to the demographic status (gender, age, marital status, current employment status and level of education attained) of the sample of 124 participants with SCI is presented in table 1.

The mean age of the sample was 32.2 years with a standard deviation of 6.31 . The ages ranged from 19 to 58 years. The majority of the sample was young adult males $(97.6 \%)$ and was under the age of 42 years. Pertaining to marital status, more than seventy percent were single compared to $27.4 \%$ that were married.

\section{Factors relating to the $\mathrm{SCI}$}

The majority of the sample (79.8\%) was paraplegics. The causes of the spinal cord injuries among the sample were many and included gunshot wounds $(64.5 \%)$ as the major cause, followed by road traffic accidents (30.4\%) falls from a height $(4.1 \%)$ and other $(1 \%)$.

\section{Occurrences of secondary complica- tions:}

The occurrence of secondary complications among the sample included pressure sores, respiratory infections, urinary tract infections and pain. These secondary medical complications are presented in table 2 .

The vast majority $(80.6 \%)$ of the sample developed pressure sores while $37.9 \%$ had urinary tract infections. Within the sample of 124 patients who were discharged from the hospital in the period 1996-2007, the majority (75.8\%) had more than one secondary medical complication pressure sores were prevalent in conjunction with other complications as is presented in table 3 .

\section{Length of hospital stay (LOS)}

The length of stay (LOS) in the hospital was calculated from the first day of

Table 1: Demographic information of the sample $(n=124)$

\begin{tabular}{|l|l|l|l|}
\hline Demographic variable & Characteristics & Frequency & $\%$ \\
\hline Gender & Male & 121 & 97.6 \\
& Female & 3 & 2.4 \\
\hline Age range & $19-24$ & 9 & 7.3 \\
& $25-30$ & 44 & 35.5 \\
& $31-36$ & 42 & 33.9 \\
& $37-42$ & 22 & 17.7 \\
& $43-48$ & 6 & 4.8 \\
& $49-54$ & 0 & 0.0 \\
& $55-60$ & 1 & 0.8 \\
\hline Marital status & Single & 90 & 72.6 \\
& Married & 34 & 27.4 \\
\hline Current employment & & & \\
status & Employed & 19 & 15.3 \\
& Unemployed & 26 & 21.0 \\
\hline Level of education & Retired & 79 & 63.7 \\
\hline
\end{tabular}

Table 2: Occurrence of secondary medical complications

\begin{tabular}{|l|l|l|}
\hline Medical Complication & Number & $\%$ \\
\hline Pressure sores & 100 & 80.6 \\
\hline Pain & 50 & 40.3 \\
\hline Urinary infection & 47 & 37.9 \\
\hline Respiratory infection & 19 & 15.3 \\
\hline
\end{tabular}

Table 3: Percentage distribution of participants with more than one medical complication $(n=94)$

\begin{tabular}{|l|l|l|}
\hline Medical complication & Frequency & $\%$ \\
\hline Pressure sores \& Urinary infections & 32 & 17.0 \\
\hline Pressure sores and bowel complications & 22 & 23.4 \\
\hline Pressure sores \& Respiratory infections & 16 & 17.0 \\
\hline Respiratory infections \& Urinary infections & 3 & 3.2 \\
\hline More than two complications & 21 & 22.3 \\
\hline
\end{tabular}

admission in the spinal cord rehabilitation unit (SCRU) to the date of discharge in years. The LOS was grouped and analyzed as 6 level categorical variables (Fig1). The length of stay (LOS) ranged from 1-12 years, with a mean length of stay in hospital rehabilitation unit of 6.56 years and a standard deviation of 2.753 years.

\section{Factors affecting LOS}

The associations between demographic variables and secondary medical complications with LOS were computed using cross tabulation and chi-square tests. A significant association was found between current employment status and $\operatorname{LOS}(\mathrm{P}$-value $=0.021)$ as well as between pressure sores and LOS ( $\mathrm{P}$-value $=0.000)$. The linear regression analysis revealed a high positive correlation between pressure sores and length of stay $(\mathrm{R}=0.703)$. Furthermore, the analysis also revealed a moderate positive correlation between employment status and length of stay $(\mathrm{R}=0.575)$.

\section{DISCUSSION}

The results of the current study show a high positive correlation between occur- 
Figure 1: Length of hospital stay among the sample.

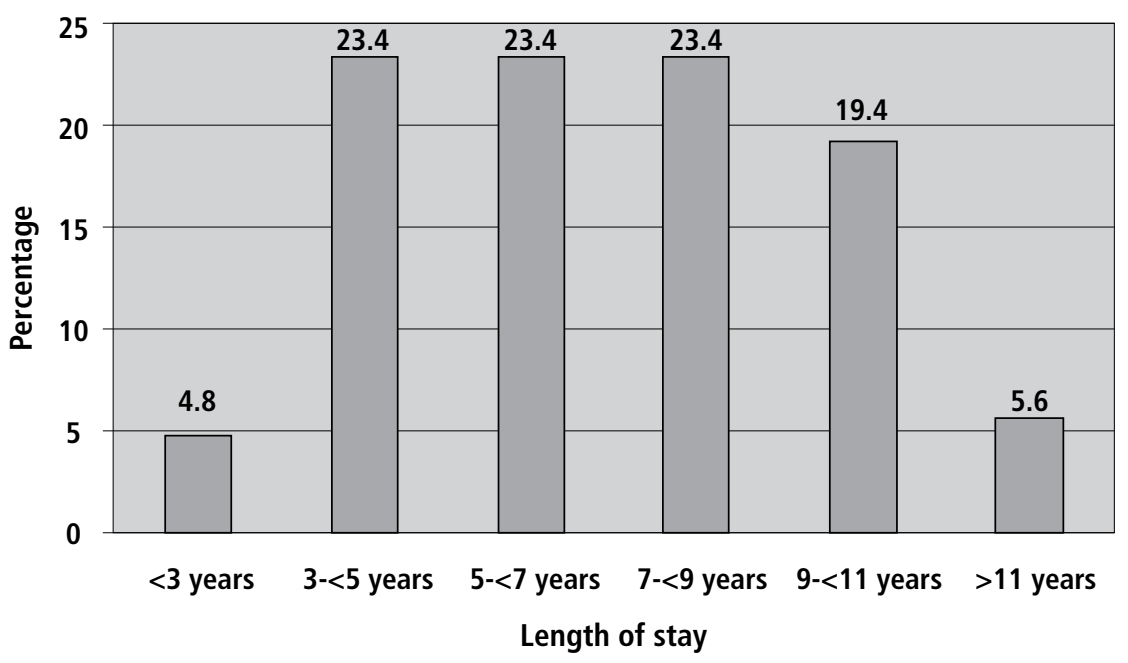

rence of pressure sores and length of stay $(\mathrm{R}=0.703)$. The occurrence of pressure sores in the participants could have been as a result of the limited number of medical personnel available to provide appropriate preventative care. Rwanda lost up to $60-80 \%$ of its health professionals during the war either as a result of death or fleeing the country (Adler et al 2004). This workforce was still not recovered at the time the study was conducted and therefore limited staff was available to care for patients. The management of pressure sores includes preventative measures, medical interventions and the use of correct equipment (Staas and Cioushi 1991). Preventative measures include correct position, pressure relief, the correct use of equipment and observing the skin for signs of increased pressure. The high occurrence of pressure sores in participants could have been as a result of a lack of implementation of preventative measures or the patients not complying with education given about pressure care. The development of pressure sores at any stage in the rehabilitation process affects the rate of progress during rehabilitation, thereby prolonging their length of stay (Ash 2002). As was the case in the present study, Regan et al (2006) stated that pressure sores are a lifelong threatening secondary medical complication of a SCI which have the potential to interfere with physical well-being, and impact on the overall quality of life.
Although pressure sores are preventable, these authors argue that their presence disrupt rehabilitation and prevent individuals with SCI from working and interfere with community integration.

Spinal cord injury patients who develop a pressure sore at any stage between injury and discharge are in hospital for an average of 177 days which is 55days longer (95\% CI 33-78. days) (Ash 2002)

The results of the current study also revealed a significant association between employment and LOS (P-value $=0.021)$ whereas other demographic data such as age, gender, level of education and marital status revealed no significant association with length of hospital stay. The majority of the participants were documented as being retired at the time of data collection. These participants were those who had been previously employed by the military and had received severance packages. They included young individuals who had not been re-employed following their injury. Despite Rwanda being a signatory of United Nations convention on the rights of persons with disabilities, and with good policies in place to promote equal participation of people with disabilities (UN, 2008), persons with disabilities still find it difficult to access jobs. The return to work rate post spinal cord injury has been reported to be as low as 33\% (van Velzen et al 2009). Factors that affect the number of people taking up employment following spinal cord injury include access to places of work, and employers' attitudes towards people with disabilities (Yasuda et al, 2002) as well as age at onset of injury, level of education and motor function (Hess et al 1999). In the current study the LOS could have been decreased if the participants could find employment and be discharged to a different setting as is discussed below. The army could still have been taking responsibility for them as they were injured in the war.

In the present study, LOS (mean = 6.56 years) was much longer when compared to what is reported in the literature. A study conducted in the Netherlands reported a LOS of 240 days (Post et al 2005) and a South African study reported a mean LOS of 73.11 days (Joseph 2011). In addition to the occurrence of pressure sores and being unemployed, another factor that could also have influenced the LOS could be a lack of discharge settings designed for care of disabled persons including those with a spinal cord injury. In Rwanda the only discharged settings available for those who could not be discharged home are mainly for the elderly and are owned by non-governmental and faithbased organizations. A lack of discharge settings may impact the ability of individuals with SCI adequate care to live in the community, (Anzai et al. 2006). Data relating to discharge planning was however not collected in the current study. Another limitation of the study was that only a limited number of personal factors that could have impacted on LOS were investigated in this study. Further studies could determine and explore other factors such as discharge planning or availability of a discharge setting which could impact on LOS.

\section{CONCLUSION}

The findings of the present study revealed that employment status, and the occurrence of pressure sores are the major factors affecting length of hospital stay among individuals with spinal cord injuries at Kanombe Military Hospital. It seems therefore that lack of preventive measures for pressure sores, including a lack of nursing staff could have contributed to the high number of 
patients with pressure influencing LOS. There is a strong need for all members of the rehabilitation team to ensure the implementation of effective measures to prevent the development of pressure sores, in patients with spinal cord injuries in the study settings. As part of this rehabilitation team physiotherapists should ensure that these preventative measures are implemented.

\section{REFERENCES}

Ackery A, Tator C, Krassioukov A 2004 A global perspective on spinal cord injury epidemiology. Journal of Neuro-trauma 2: 1355-1370

Adler N, Smith J, Fishman P, Larson B 2004 To Prevent, React, and Rebuild: Health Research and the Prevention of Genocide. Health Services Research 39:20272051

Anzai K, Young Y, McCallum Miller B, Jongbleod L 2006 Factors influencing discharge location following high lesion spinal cord injury rehabilitation in British Colombia Canada. Spinal Cord 44:11-18

Ash D 2002 An exploration of the occurrence of pressure ulcers in a British spinal injuries unit. Journal of Clinical Nursing 11: 470-478

Celani M, Spizzichino L,Ricci S, Zampolini M, Franceschini M 2001 Spinal Cord Injury in Italy: a multicentre retrospective study. Archives of Physical Medicine and Rehabilitation 82:589-596

Chappell P, Wirz S 2003 Quality of life following spinal cord injury for 20-40 year old males in Sri Lanka. Asia Pacific Disability Rehabilitation Journal 14:87-110

Garber S, Rintala D 2003 Pressure ulcers in veterans with spinal cord injury: A retrospective study. Journal of Rehabilitation Research and Development 40: 433-442

Hess D, Ripley L, Mckinley W,Tewbury M. 1999 Predictors for return to work after spinal cord injury: A 3-year multicentre analysis. Accessed 10 April, 2012 from http://dx.doi.org/10.1016/ S0003-9993(00)90084-4.

Henn R, Visagie S, Mji G 2012 Rehabilitation Outcomes of Persons with Complete Paraplegia at a Private Rehabilitation Hospital. South African Journal of Physiotherapy 68:15-21

Herm B, Spackman J, Anderson A 2000 Experience with family supported rehabilitation of people with spinal cord injury. Asian Pacific Disability Rehabilitation Journal 1:1
Joseph C 2011 Determining the Process of Rehabilitation and the Outcomes of Patients at a Specialized In-Patient Centre in the Western Cape Unpublished master's Thesis University of the Western Cape, South Africa

Kirchberger I, Sinnot A, Charlifue S, Kovindha A, Lûthi H, Cambell R, Zwecker M, Scheuringer M, Cieza A 2010 Functioning and Disability in spinal cord injury from the consumer perspective: an international qualitative study using focus groups and the ICF. Spinal Cord 48:603-613

Kautzky K \& Tollman S 2008 A perspective on Primary Health Care in South Africa. In Health Systems Trust (Eds.) South African Health Review 2008. Durban: HST

Middleton J, Lim K, Taylor L, Soden R, Rutkowiski S. 2004 Patterns of morbidity and rehospitalisation following spinal cord injury. Spinal Cord 42: 359-365

New P, Rawicki H, Bailey M 2002 Nontraumatic spinal cord injury: demographic characteristics and complications. Archives of Physical Medicine and Rehabilitation 83:996-1001

Post M, Dallmoeijer J, Angenot Van Asback E, Van der Wounde F 2005 Duration and functional outcome of spinal cord injury rehabilitation in the Netherlands. Journal of Rehabilitation Research \& Development 42: 75-86.

Ragnarrsson K, Wuermser L, Cardenas D, Marino R 2005 Spinal cord clinical trials for neurologic restoration: Improving care through clinical research. American Journal of Physical Medicine and Rehabilitation 8: 77-100

Regan M, Teasell R, Keast D, Mortenson W, Aubut J. 2006 Pressure ulcers following spinal cord injury. Spinal Cord 40:433- 442

Ronen J, Itzikovich K, Bluvshtein V, Thaleisnik M, Goldin D, Garernter I, David R, Gepstein R 2004. Length of stay in Hospital following spinal cord lesion in Israel. Spinal Cord 42: 353-358

Savic G, Short D, Weitzenkamp D, Charlifue S, Gardner B 2000 Hospital readmissions in people with chronic spinal cord injury. Spinal Cord 38:371-377

Scheuringer M, Kirchberger I, Eriks-Hoogland I, Rauch A, Velstra I-M, Cieza A 2010 Identification of problems in individuals with spinal cord injury from the health professional perspective using the ICF: a worldwide expert survey. Spinal Cord 48:529-536

Simpson S, Packer C, Stevens A, Raftery J 2005 Predicting the impact of new technologies on average length of stay: Development of a prediction framework. International Journal of Tech- nology Assessment in Health Care 21: 487-491 Staas W Jnr, Cioschi H 1991 Pressure Sores-A Multifaceted Approach to Prevention and Treatment. West Journal of Medicine 154:539-544

van Langeveld $\mathrm{S}$, Post $\mathrm{M}$, van Asbeck $\mathrm{F}$, Gregory M, Halvorsen A, Rijken H, Leenders J, Postma K, Lindeman E 2011 Comparing Content of Therapy for People With a Spinal Cord Injury in Postacute Inpatient Rehabilitation in Australia, Norway and the Netherlands Physical therapy 91:210-224

van Velzen J, de Groot S, Post M, Slootman J, van Bennekom C, van der Woude L 2009 Return to work after spinal cord injury: is it related to wheelchair capacity at discharge from clinical rehabilitation $<$ Archives of Physical Medicine and Rehabilitation 88:1035-1036

United Nations convention on the rights of persons with disabilities 2008. Retrieved on 22.02.2012 from http://www.un.org/disabilities/ default

Yasuda S, Wehman P, Targett P, Cifu D, West M 2002 Return to work after spinal cord injury: A review of recent research. NeuroRehabilitation 17:177-186.

Wong E, Cheung A, Yam C Chan F, Wong F, Yeoh E 2011 Unplanned readmission rates, length of hospital stay, mortality, and analysis of Hong Kong hospital data. BMC Health Services Research Retrieved on 10.04.2012 from http:// w02.biomedcentral.com/1472-6963/11/149 